\title{
Diffusion and crystallization mechanisms of Ge/Au bilayer media for write-once optical disk
}

\author{
T. H. Wu, P. C. Kuo, a) and S. L. Ou \\ Institute of Material Science and Engineering, National Taiwan University, Taipei 106, Taiwan \\ Jung-Po Chen, Po-Fu Yen, and Tzuan-Ren Jeng \\ Electronics and OptoElectronics and Research Laboratories, Industrial Technology Research Institute, \\ Hsinchu 310, Taiwan \\ Chih-Yuan Wu \\ Department of Physics, Fu Jen Catholic University, Hsinchuang 242, Taiwan \\ Der-Ray Huang \\ Hsinchu Science Based Industrial Park, Hsinchu 300, Taiwan
}

(Received 7 August 2007; accepted 14 December 2007; published online 10 January 2008)

\begin{abstract}
$\mathrm{Ge} / \mathrm{Au}$ bilayer thin films were fabricated by magnetron sputtering method, the temperature dependence of resistance from room temperature to $500{ }^{\circ} \mathrm{C}$ and concentration depth profiles are measured. From the temperature dependence of resistance measurement, we found two phase change phenomena which occurred at 175 and $360{ }^{\circ} \mathrm{C}$. The element concentration depth profiles of the as-deposited and recorded region indicate that the $\mathrm{Au}-\mathrm{Ge}$ alloy is initially formed at the $\mathrm{Ge} / \mathrm{Au}$ interface. The dominant diffusion element is Au atom and the diffusion path is from Au layer to Ge layer. The optimum simulated bit error rate value is about $1.4 \times 0^{-6}$ at $9.0 \mathrm{~mW}$ under two time high definition digital versatile disk (HD DVD) recording speed. The dynamic tests show that this $\mathrm{Ge} / \mathrm{Au}$ bilayer films can be applied to one to two times HD DVD-R. () 2008 American Institute of Physics. [DOI: $10.1063 / 1.2831690]$
\end{abstract}

Recently, the optical disk was improved due to the needs of large information transformation and high definition media resolution. Blu-ray disc (BD) and high definition digital versatile disk (HD DVD) had been proposed as the promising candidates. Various inorganic recording media were reported for them. The jitter value of $\mathrm{Bi}-\mathrm{Ge}$ nitride ${ }^{1}$ was found only 5.7\% under 36-72 Mbps writing speed. Te-O-Pd (Ref. 2) was proposed as a four layer recording media for 100 Gbyte BD system. The bilayer structure, such as amorphous silicon $(a-\mathrm{Si}) /$ metal $^{3-6}$ have also been studied. Although the relationship between microstructure and annealing temperature of $a-\mathrm{Ge} / \mathrm{Au}$ had been discussed previously, ${ }^{5}$ the diffusion mechanism of $\mathrm{Ge} / \mathrm{Au}$ bilayer during recording is not identified.

In this paper, the diffusion and crystallization mechanisms of $a-\mathrm{Ge} / \mathrm{Au}$ bilayer media for write-once HD DVD disks are investigated. Two steps of phase change are found by measuring the variation of electrical resistance with temperature. The element concentration depth profiles of the asdeposited and recorded region, which were measured by Auger electron spectrometer (AES), indicate that the diffusion path was from $\mathrm{Au}$ layer to $\mathrm{Ge}$ layer.

The resistance of $\mathrm{Ge} / \mathrm{Au}$ bilayer with nature oxidized (110) silicon wafer substrate was measured by the four-probe resistance tester in vacuum. Figure 1(a) shows the layer structure of the sample. The $a-\mathrm{Ge}(10 \mathrm{~nm}) / \mathrm{Au}(10 \mathrm{~nm}) \mathrm{bi}-$ layer for AES investigation was prepared by magnetron sputtering on polycarbonated (PC) substrate, as shown in Fig. 1(b). The sample with PC substrate was then laser initialized, and the variation of its reflectivity with wavelength was mea-

${ }^{a)}$ Author to whom correspondence should be addressed. Tel.: +886-223648881. Fax: +886-2-23634562. Electronic mail: pckuo@ntu.edu.tw. sured by spectrometer (ETA-RT, Optik's high sensitive spectrometer). The initialized sample, which has the largest optical contrast at $\lambda=405 \mathrm{~nm}$ (comparing with the as-deposited sample), is selected for the AES measurement. The element concentration depth profile was measured by AES with sputtering speed of $0.2 \mathrm{~nm} / \mathrm{s}$. The recording characteristics were evaluated by dynamic tester (ODU1000, PULSTEC), which the testing conditions are shown in Table I.

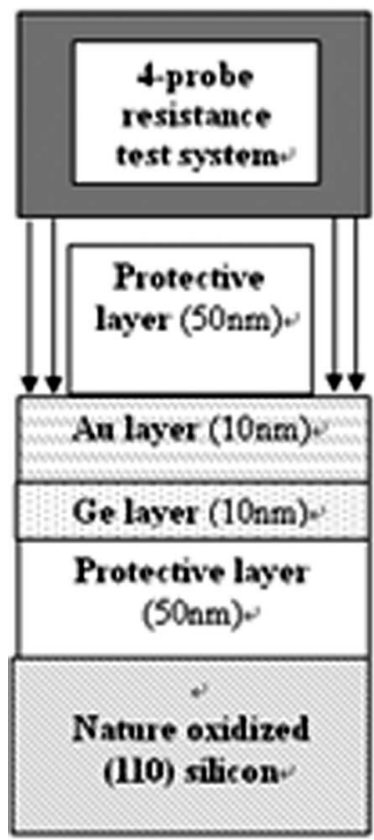

(a).

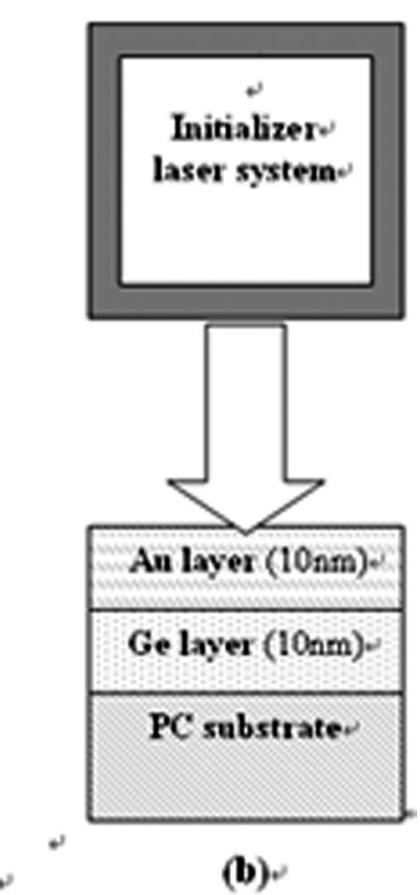

FIG. 1. The layer structure of samples for (a) resistance measurement and (b) AES depth profile measurement. 
TABLE I. Dynamic test conditions.

\begin{tabular}{|c|c|c|c|c|c|c|c|c|}
\hline $\begin{array}{c}\text { User } \\
\text { capacity }\end{array}$ & $\begin{array}{l}\text { Thickness } \\
\text { of substrate }\end{array}$ & Wavelength & $\begin{array}{c}\text { Numerical } \\
\text { aperture (NA) }\end{array}$ & $\begin{array}{l}\text { Modulation } \\
\text { code }\end{array}$ & $\begin{array}{l}\text { Track } \\
\text { pitch }\end{array}$ & $\begin{array}{l}\text { Channel clock } \\
\text { frequency }\end{array}$ & $\begin{array}{l}\text { Linear } \\
\text { velocity }\end{array}$ & $\begin{array}{l}\text { User bit } \\
\text { rate }\end{array}$ \\
\hline $15 \mathrm{~GB}$ & $0.6 \mathrm{~mm}$ & $405 \mathrm{~nm}$ & 0.65 & $\begin{array}{l}\text { ETM, RLL } \\
\quad(1,10)\end{array}$ & $0.4 \mu \mathrm{m}$ & 64.8 Mhz & $13.2 \mathrm{~m} / \mathrm{s}$ & $73.1 \mathrm{Mbps}$ \\
\hline
\end{tabular}

Figure 2 shows the variation of resistance with temperature. The $\mathrm{Ge} / \mathrm{Au}$ bilayer film has two phase transformation temperatures which are 175 and $360{ }^{\circ} \mathrm{C}$. The first phase change temperature corresponds to the interdiffusion of the bilayers. ${ }^{5}$ Since the probes touch the surface of Au layer, as shown in Fig. 1(a), the measured resistance represents $\mathrm{Au}$ layer's behavior. The resistance increases with decreasing Au layer's thickness (Ohm's law, $R=\rho L / A$, where $\rho=$ resistivity, $L=$ sample length, and $A=$ cross sectional area). The expansion of $\mathrm{Ge} / \mathrm{Au}$ interface layer and the new forming discontinuous phase by interdiffusion of $\mathrm{Au}$ and $\mathrm{Ge}$ atoms resulted in the rising of resistivity at $175^{\circ} \mathrm{C}$. So, the crystallization temperature of $\mathrm{Ge}$ is decreased from 473 (Ref. 7) to $175^{\circ} \mathrm{C}$. This mechanism is called the metal induced crystallization (MIC) mechanism. ${ }^{3-6,8}$ From the observation of high resolution transmission electron microscope, ${ }^{5}$ rearranging atoms of the breaking of $\mathrm{Au}-\mathrm{Ge}$ bonds and precipitation of $\mathrm{Ge}$ were found at $340{ }^{\circ} \mathrm{C}$. However, from our resistance measurement, it shows no further phase change higher than $175^{\circ} \mathrm{C}$, until the temperature approaches to the eutectic temperature of $\mathrm{Ge} / \mathrm{Au}\left(363^{\circ} \mathrm{C}\right) .{ }^{9}$ This owes to the low solubility of $\mathrm{Au}$ in crystalline $\mathrm{Ge}(13.6 \mathrm{ppm}),{ }^{10}$ the metal induced crystallites of $\mathrm{Ge}$ hinder the further diffusion of $\mathrm{Au}$ into $\mathrm{Ge}$ at temperature between 175 and $360{ }^{\circ} \mathrm{C}$, until the temperature approaches to the eutectic temperature of $\mathrm{Ge} / \mathrm{Au}\left(363{ }^{\circ} \mathrm{C}\right)$, the $\mathrm{Ge} / \mathrm{Au}$ films show another phase transformation.

In order to identify the atom's migration direction between $\mathrm{Au}$ and Ge layers during diffusion, the element depth profiles of as-deposited and recorded samples were measured by AES. Figure 3 shows the depth profile of $\mathrm{Ge} / \mathrm{Au}$ bilayer. The total sputtering time is $100 \mathrm{~s}$, which corresponds to about $20 \mathrm{~nm}$ depth from the surface. The film was composed

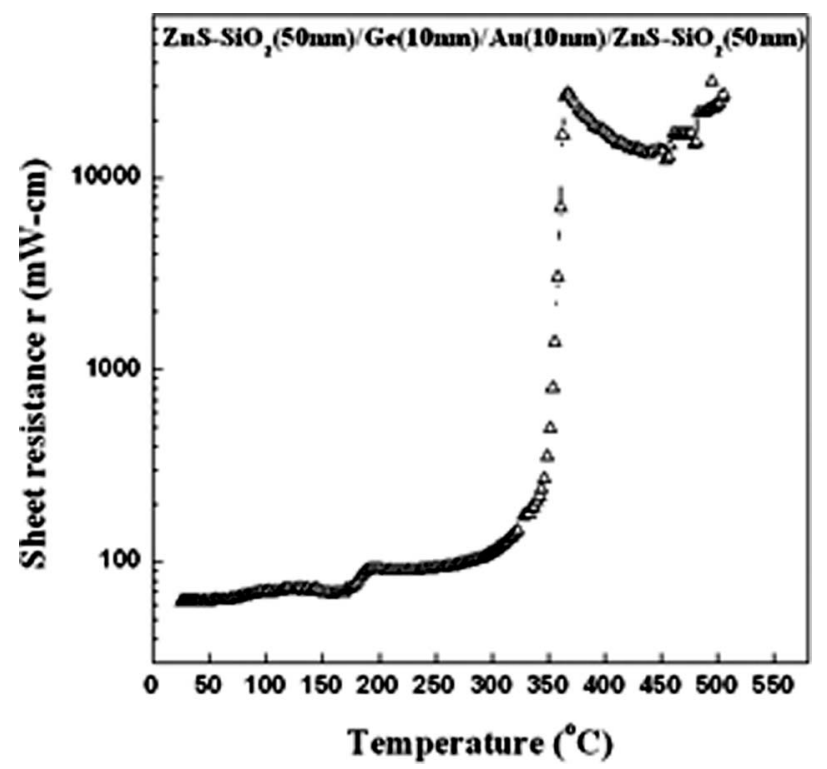

FIG. 2. Relationship between the electric resistance and temperature of $\mathrm{Ge} / \mathrm{Au}$ bilayer.

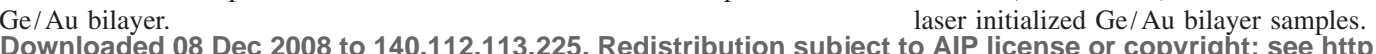

by three layers, which are the Au layer, the Ge/Au interface layer, and the Ge layer. Significantly, the Au-Ge interlayer was formed initially. In 1989, Hou et al. ${ }^{11}$ had discussed the heterogeneous nucleation and the random found limited mass transport at $\mathrm{Au} / \mathrm{Ge}$ interlayer. In our examination, the diffusion path has been further revealed

Figures 4 and 5 are the Ge and Au concentration depth profiles of as-deposited and laser initialized in the $\mathrm{Ge} / \mathrm{Au}$ bilayers, respectively. During the first $30 \mathrm{~s}$ of the sputtering (about $0-6 \mathrm{~nm}$ depth), the two curves in Fig. 4 remain extremely low. The Ge atoms did not diffuse to such depth after laser initialized. However, between 30 and $40 \mathrm{~s}$ (about 6-8 $\mathrm{nm}$ depth), the Ge concentration in laser recorded sample is slightly larger than that of the as-deposited sample. After that, although these two curves increase with the depth, the Ge concentration of laser initialized sample is lower than that of as-deposited sample. On the other hand, the Au atoms diffused into Ge layer as the depth deeper than $16 \mathrm{~nm}$ (sputtering time is longer than $80 \mathrm{~s}$ ), as shown in Fig. 5. At the sputtering time of 30-40 s (about 6-8 nm depth), the $\mathrm{Au}$ concentration of laser recorded sample is slightly smaller than that of the as-deposited sample. These two curves decrease further as the sputtering time is increased again. However, the $\mathrm{Au}$ concentration of laser initialized sample is higher than that of as-deposited sample at sputtering time of $40-80 \mathrm{~s}$ (depth of $8-16 \mathrm{~nm}$ ). Those results indicate that the Ge atoms did not obviously diffuse to the Au layer, the dominant diffusion element is $\mathrm{Au}$ and the diffusion path is from $\mathrm{Au}$ layer to $\mathrm{Ge}$ layer during recording. Au-Ge bonds were formed by $\mathrm{Au}$ interdiffusion. The broken metastable $\mathrm{Au}-\mathrm{Ge}$ bonds were established during recording facilitated the local rearrangement. ${ }^{12}$ Since the solubility of $\mathrm{Au}$ in crystallized Ge is low, the Au atoms will be squeezed out as the Ge crystallizes growing. The dependence between the metal thickness and the $a$-Ge layer was discussed. ${ }^{13}$ The MIC mechanism only affected the metal $/ a-\mathrm{Ge}$ interface which was located

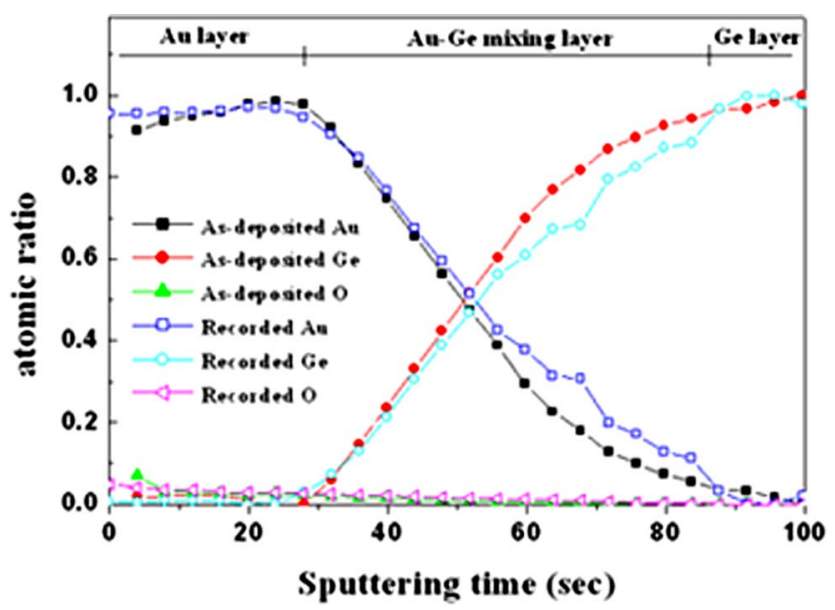

FIG. 3. (Color online) The concentration depth profile of as-deposited and

laser initialized Ge/Au bilayer samples. 


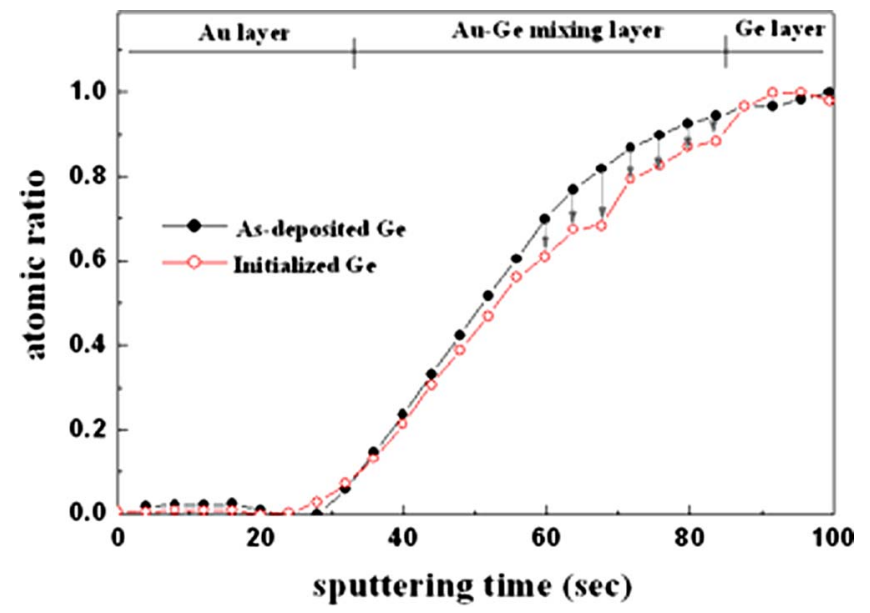

FIG. 4. (Color online) The concentration depth profile of as-deposited and laser initialized $\mathrm{Ge}$ atoms in the $\mathrm{Ge} / \mathrm{Au}$ bilayer samples.

close to the bilayers. By the AES result, the diffusion limitation is revealed. Au atoms diffused into $8 \mathrm{~nm}$ depth of $\mathrm{Ge}$ layer, which resulted in the optical contrast between asdeposited and laser pulsed state.

Figure 6 shows the simulated bit error rate (SbER) value $5^{5}$ and the modulation of the $\mathrm{Ge} / \mathrm{Au}$ bilayer compared with the laser powers. The SbER value is decreased from $1.2 \times 10^{-5}$ to $1.4 \times 10^{-6}$ as the writing power increased from 8.3 to $9.0 \mathrm{mw}$, and then further increased to $2.0 \times 10^{-5}$ as the writing power increased to $9.6 \mathrm{mw}$. Meanwhile, the modulation is about $0.77-0.78$. SbER value was suggested to be lower than $1 \times 10^{-5}$. The optimum SbER value in our dynamic test is $1.4 \times 10^{-6}$ which occurred at about $9.0 \mathrm{~mW}$ under two times HD DVD recording speed that means the $\mathrm{Ge} / \mathrm{Au}$ bilayer recording thin film is suitable for two times HD DVD write-once disk.

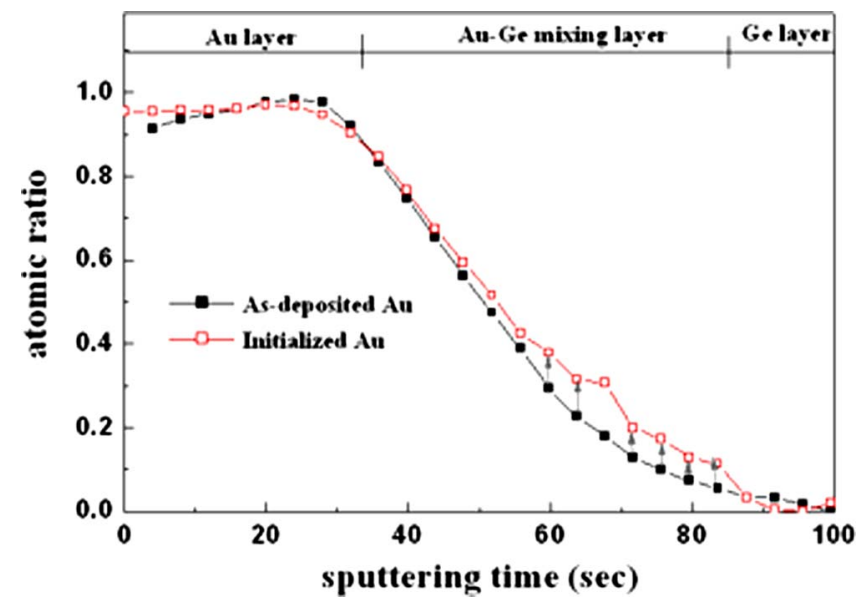

FIG. 5. (Color online) The concentration depth profile of as-deposited and laser initialized $\mathrm{Au}$ atoms in the $\mathrm{Ge} / \mathrm{Au}$ bilayer samples.

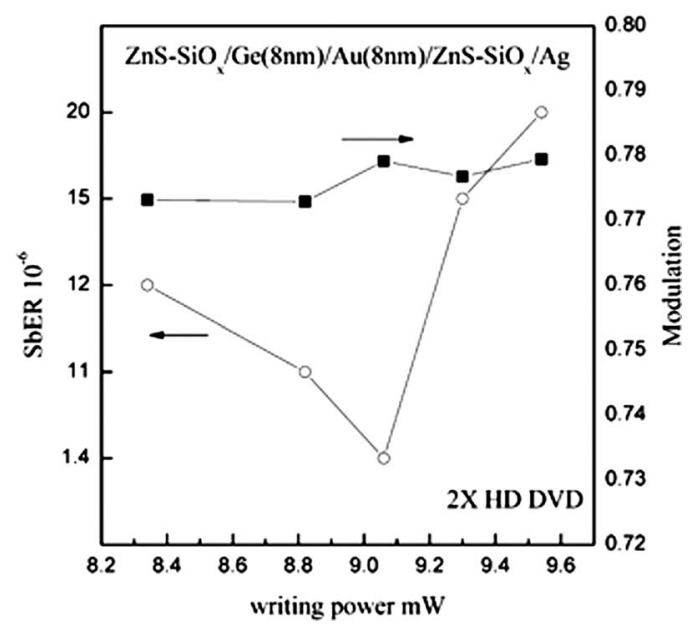

FIG. 6. SbER value and modulation of the $\mathrm{Ge} / \mathrm{Au}$ bilayer medium as a function of writing power. The track pitch is $0.4 \mu \mathrm{m}$.

In summary, recording properties of $a-\mathrm{Ge} / \mathrm{Au}$ writeonce optical media had been studied. From the four-probe resistance measurement, it is found that the crystallization temperature of $\mathrm{Ge}$ will be reduced from 473 to $175^{\circ} \mathrm{C}$ by the interdiffusion of $\mathrm{Au}$ atoms. The AES inspection proves that the dominant diffusion element is $\mathrm{Au}$ and the diffusion path is from Au layer to Ge layer during recording. Dynamic tests show that the optimum SbER is $1.4 \times 10^{-6}$ which occurred at about $9.0 \mathrm{~mW}$ under two times HD-DVD recording speed.

This work was supported by the National Science Council and Ministry of Economic Affairs of Taiwan through Grant Nos. NSC 95-2221-E-002-115 and 95-EC-17-A-08S1-0006.

${ }^{1}$ Y. Hosoda, T. Izumi, A. Mitsumori, F. Yokogawa, S. Jinno, and H. Kudo, Jpn. J. Appl. Phys., Part 1 42, 1040 (2003).

${ }^{2}$ K. Kimura and E. Ohno, Jpn. J. Appl. Phys., Part 1 28, 2223 (1989).

${ }^{3}$ Y. C. Her, S. T. Jean, and J. L. Wu, J. Appl. Phys. 102, 093503 (2007).

${ }^{4}$ H. Inoue, K. Mishima, M. Aoshima, H. Hirata, T. Kato, and H. Utsunomiya, Jpn. J. Appl. Phys., Part 1 42, 1059 (2003).

${ }^{5}$ T. H. Wu, P. C. Kuo, J.-P. Chen, C.-Y. Wu, P.-F. Yen, T.-R. Jeng, D.-R. Huang, and Y.-H. Fang, Appl. Phys. Lett. 90, 151111 (2007).

${ }^{6}$ Y.-C. Her, C.-W. Chen, and C.-L. Wu, J. Appl. Phys. 99, 113512 (2006).

${ }^{7}$ F. Oki, Y. Ogawa, and Y. Fujiki, Jpn. J. Appl. Phys. 8, 1056 (1969).

${ }^{8}$ S. W. Russell, J. Li, and J. W. Mayer, J. Appl. Phys. 70, 5153 (1991).

${ }^{9}$ Binary Alloys Phase Diagrams, 2nd ed., edited by B. Thaddeus, J. L. Murray, L. H. Bennett, and H. Baker (American Society for Metals, Metals Park, OH, 1986), Vol. 1, p. 373.

${ }^{10}$ H. Okamoto and T. B. Massalski, Bull. Alloy Phase Diagrams 5, 601 (1984).

${ }^{11}$ J. G. Hou, Z. Q. Wu, and L. S. Bi, Thin Solid Films 77, 173 (1989).

${ }^{12}$ Z. Tan, S. M. Heald, M. Rapposch, C. E. Bouldin, and J. C. Woicik, Phys. Rev. B 46, 9505 (1992).

${ }^{13}$ G. Radnoczi, A. Robertsson, H. T. G. Hentzell, S. F. Gong, and M.-A. Hasan, J. Appl. Phys. 69, 6394 (1991). 